Eixo Temático: Processos de Ensino-Aprendizagem

\title{
ET-06-009 \\ AUTOAVALIAÇÃO NO ESTÁGIO DE DOCÊNCIA DE BIOLOGIA: UM ESTUDO DE CASO
}

Brenna Pinheiro Bastos¹, Cláudia Regina Teixeira de Souza²

${ }^{1}$ Graduanda em Ciências Biológicas. Universidade do Estado da Bahia, Campus II. AlagoinhasBA.

${ }^{2}$ Professora Adjunto. Departamento de Ciências Exatas e da Terra. Universidade do Estado da Bahia, Campus II, Alagoinhas-BA.

http://dx.doi.org/10.21472/congrebio2016.et-06-009

\section{RESUMO}

Durante o Estágio Supervisionado tem-se a oportunidade de aprendizagem social, profissional e cultural, através da participação em atividades de trabalho vinculadas à área de formação acadêmico-profissional. Nesse sentido, foi realizado o estágio de regência no Colégio Modelo Luís Eduardo Magalhães, no Município de Alagoinhas-BA, visando a estabelecer uma relação teórico-prática no ensino de Biologia, bem como de aprendizagem da docência, durante o período de outubro a dezembro de 2015 em uma turma do primeiro ano do Ensino Médio, no turno matutino. A partir da experiência do estágio de regência, vivenciada pela primeira autora no Estágio Supervisionado II, componente curricular do Curso de Licenciatura em Ciências Biológicas na Universidade do Estado do Estado da Bahia (UNEB), o presente trabalho teve por objetivo investigar quais medidas são eficientes na avaliação na carreira do profissional docente e do estagiário, em função do processo ensino-aprendizagem dos alunos. É um estudo de natureza qualitativa, que se insere na metodologia de um estudo de caso. O estágio permitiu o estabelecimento da relação dialética entre teoria e prática, bem como entre professores (supervisor e regente) com a estagiária, e, além disso, a compreensão acerca da importância da autoavaliação docente para um melhor desenvolvimento profissional e consequentemente, profissionalização.

Palavras-chave: Autoavalição docente; Estágio Supervisionado no Ensino Médio; EnsinoAprendizagem.

\section{INTRODUÇÃO}

Os estágios supervisionados são importantes nos currículos dos Cursos de Licenciatura no Brasil, uma vez que permite a integração da teoria e da prática, além de se constituir como oportunidades de vivências específicas da docência. Durante o estágio, tem-se a oportunidade de aprendizagem social, profissional e cultural, através da participação em atividades de trabalho vinculadas à área de formação acadêmico-profissional. Na Universidade do Estado da Bahia (UNEB) - Campus II, o estágio realizado no componente curricular Estágio Supervisionado II tem o caráter de pesquisa da prática.

Segundo Pimenta e Lima (2004), o estágio nos cursos de formação de professores deve possibilitar que os futuros docentes compreendam a complexidade das práticas institucionais e das ações exercidas pelos profissionais como um modo de preparação para sua inserção profissional, porém só é possível se o estágio constituir um eixo de todas as disciplinas do curso, que tem de contribuir para formar professores por meio da análise, do pensamento e da problematização de suas práticas, atuando assim como um professor reflexivo ou professor pesquisador de sua prática. Corroboramos com as autoras supracitadas, bem como com Alarcão (2011), que traduz a necessidade do ser humano se questionar como sendo "um motor de 
desenvolvimento e de aprendizagem” (p. 62). Questionar sua prática docente através de mecanismos de escrita, reflexão e discussões em grupo, a partir de teorias estudadas, alicerça a aprendizagem da docência, e em consequência traz mais qualidade ao ensino.

Nesse sentido, foi realizado o estágio de regência, no Colégio Modelo Luís Eduardo Magalhães, no município de Alagoinhas - BA, visando estabelecer uma relação teórico-prática no ensino de Biologia.

A partir da vivência de sala de aula da primeira autora no estágio e, sobretudo, do desempenho dos alunos na verificação de aprendizagem em biologia, se estimulou o estudo do desempenho da docência (através do estudo de caso) para mensurar até que ponto o professor é responsável pelos resultados negativos dos alunos no processo de avaliação, tendo em vista estudos realizados com o tema em vários países.

Sendo assim, o presente trabalho teve por objetivo investigar, com base na literatura e, principalmente, a partir da experiência do estágio de regência no ensino de Biologia, quais as medidas de avaliação são eficientes na carreira do profissional docente e do estagiário, em função do processo ensino-aprendizagem dos alunos.

\section{METODOLOGIA}

O estudo assumiu os princípios do paradigma qualitativo e a forma de um Estudo de Caso. Para a construção dos dados, utilizou-se o diário de bordo (portfólio) onde foram registradas as observações sobre a experiência vivenciada. Neste estudo, portanto, é descrito o estágio de regência da primeira autora, bem como isso impactou no desenvolvimento profissional docente (inicial) e no alicerce da afirmação de querer ser professora.

O estágio foi realizado no período de outubro a dezembro de 2015, compreendendo a IV Unidade do ano letivo, em uma turma do primeiro ano do Ensino Médio do Colégio Modelo Luis Eduardo Magalhães, no município de Alagoinhas - BA, no turno matutino, sob a supervisão da professora regente Neide Sales dos Santos. O público alvo foi composto por 43 alunos.

O Colégio Modelo Luis Eduardo Magalhães atende ao Ensino Médio regular nos turnos matutino, vespertino e noturno. Inaugurado em 12 de março de 2001, possui no total mais de 10 anos de história contribuindo para a educação no município de Alagoinhas e tem por finalidade oferecer a seus alunos serviços educacionais com base nos princípios emanados das Constituições Federal e Estadual e da Lei de Diretrizes e Bases da Educação Nacional. De modo geral, a infraestrutura do colégio contribui para boas condições de trabalho e oferece um bom suporte para os professores, sendo um espaço agradável e de boa convivência.

O estágio supervisionado foi realizado em três etapas: a observação da turma nas aulas, as coparticipações e em seguida a regência do ensino de Biologia, dando continuidade ao conteúdo programático do ano letivo.

A primeira etapa, que compreendeu as observações das aulas, foi de extrema importância para o reconhecimento do local enquanto espaço físico; a familiarização com os alunos, professores e funcionários da escola; e a verificação dos recursos disponíveis para implementar a prática pedagógica no período de co-participação e principalmente no período da regência. Esse momento propicia à estagiária o conhecimento sobre o perfil da turma para posterior elaboração de estratégias mais eficientes para o processo ensino-aprendizagem.

Na etapa seguinte, as coparticipações, teve-se a oportunidade de trabalhar diretamente com os alunos no papel de auxiliar o regente, nas quais a execução das atividades escolares é dividida entre o professor e o estagiário, que o auxilia nas atividades que for solicitado.

A última etapa do estágio supervisionado foi a regência, momento em que a estagiária assume a sala de aula, sob a orientação, acompanhamento e avaliação da professora regente da disciplina e na qual se teve a oportunidade de conduzir as aulas, vivenciando como se dá o processo de ensino e aprendizagem. Na etapa de regência, a princípio, foi apresentado aos alunos o cronograma das atividades que seriam realizadas, citando os conteúdos e as formas de avaliação que seriam trabalhadas na Unidade. Em seguida foram estabelecidos os objetivos de 
cada aula, visando a otimização da participação dos estudantes, conforme estabelecido no plano de aula. Foram definidas diferentes estratégias, com base nos conteúdos, visando a elaboração de uma aula mais dinâmica: jogos, vídeos, convidar os alunos para participar escrevendo na lousa e demonstrações didáticas.

Sendo assim, foram realizadas atividades individuais e em grupo, o que permitiu a avaliação da aprendizagem do estudante, como também o seu desempenho na dinâmica do grupo.

Realizou-se, ainda, uma autoavaliação da docência no estágio supervisionado a fim de mensurar a eficiência da docência.

\section{RESULTADOS E DISCUSSÃO}

De modo geral, a turma estabeleceu uma boa relação com a professora regente e a estagiária, tiravam dúvidas sobre o conteúdo e respondiam às perguntas, sendo as primeiras etapas anteriores à regência essenciais para a elaboração de estratégias, visando uma aprendizagem mais significativa dos conteúdos.

Durante o estágio de regência, no entanto, o desempenho dos alunos na verificação de aprendizagem da disciplina de biologia foi muito abaixo do esperado, no qual apenas cinco alunos obtiveram a média para serem aprovados, o que representa $16 \%$ do total de alunos que frequentavam as aulas (31 alunos). Além disso, apenas 17 alunos da turma entregaram parte das atividades solicitadas.

Diante de tais problemáticas, a busca por medidas avaliativas justas do desempenho da docência é de extrema importância para os profissionais docentes (estagiários ou não), que devem estar constantemente avaliando suas práticas.

De acordo com a literatura, constatou-se que o mau desempenho dos alunos nas avaliações da disciplina de Biologia não se limitava à turma em que foi realizado o estágio supervisionado, mas trata-se de uma questão muito mais abrangente: o baixo desempenho dos alunos brasileiros nas avaliações nacionais e internacionais. Dados divulgados pela Organização para a Cooperação e Desenvolvimento Econômico (HANUSHEK e WOESSMANN, 2015), revelam que em um ranking mundial de qualidade de educação entre 76 países avaliados, 0 Brasil encontra-se na posição $60^{\mathrm{a}}$, entre os 20 piores resultados. Em pesquisas mais recentes, também divulgadas pela OCDE (2016), o relatório sobre o desempenho dos estudantes de 64 países e territórios revela que o Brasil está entre os dez piores do mundo, com rendimento escolar baixíssimo em matemática, leitura e ciências. São dados realmente alarmantes e que demonstram o nível da educação no Brasil em relação aos demais países.

De modo geral, os resultados das avaliações da aprendizagem interessam a quatro públicos: (i) aos alunos, que tem o direito de conhecer o próprio processo de aprendizagem para se empenhar na superação das necessidades; (ii) aos pais dos alunos, corresponsáveis pela educação dos filhos e por parte significativa dos estímulos que eles recebem; (iii) à equipe de gestão escolar, que tem o dever de garantir a continuidade e coerência no percurso escolar de todos os estudantes; (iv) ao professor, que precisa avaliar constantemente a própria prática de sala de aula.

No aspecto da avaliação docente, em particular, Fernandes (2008) apresenta três diferentes abordagens de avaliação com diferentes focos: avaliação da qualidade dos professores focalizada na análise da competência, isto é, no sistema de saberes diversificados e específicos que eles dominam, utilizam ou em que acreditam; avaliação da qualidade do ensino focalizada na análise do desempenho dos professores e associada ao que o professor efetivamente faz, como ensinar, preparar aulas, participar de reuniões e conselhos de classes; e a avaliação da eficácia dos professores focalizada na análise dos resultados dos seus alunos e, portanto, no seu efeito sobre o que os alunos são capazes de responder em determinadas situações. Segundo o autor, ainda, a avaliação docente tem por finalidade melhorar o desempenho dos professores, a responsabilização e prestação pública de contas, melhorar práticas e procedimentos das escolas, compreender problemas de ensino e aprendizagem, contribuindo para a identificação de 
soluções possíveis e compreender as experiências vividas por quem está envolvido numa dada prática social.

Partindo desses pressupostos, pode-se constatar que o resultado dos alunos nas avaliações é apenas um dos aspectos relacionados ao desempenho docente. Conforme descrevem Flores e Simão (2009), a autoavaliação docente perpassa pela autocompreensão dos professores, caracterizada por cinco componentes: (i) a auto-imagem, que constitui a forma como os professores tipificam a si próprios; (ii) a auto-estima, relacionada a apreciação do seu desenvolvimento profissional como professores; (iii) a percepção da tarefa, que engloba a noção que o professor tem daquilo que constitui o seu programa profissional, as suas tarefas e os seus deveres de modo a pode desempenhar bem a sua função; (iv) a motivação profissional, referente às razões ou caminhos que levam as pessoas a tornarem-se professores; (v) a perspectiva futura, que revela as expectativas dos professores sobre o seu futuro na profissão.

No entanto, a busca por formas mais justas de se conhecer a eficiência do profissional docente (estagiário ou não), se torna polêmica na medida em que se confronta com a inconsistência do que deve ser considerado um bom modelo de aferição. Além de contemplar a avaliação de todas as atribuições do professor (que, no geral, ainda não foram sistematizadas), esse modelo precisa incorporar o contexto (socioeconômico e cultural, por exemplo) em que esse profissional trabalha. De acordo com Carnoy:

O problema no Brasil e no Chile (e na maioria dos países latino-americanos) é que não existem padrões claros do que se considera um ensino de boa qualidade e há pouca avaliação de desempenho docente mesmo entre os estudantes do magistério e dos próprios professores no início de carreira. $\mathrm{Na}$ maioria das profissões existe, no mínimo, medidas de resultado do trabalho. [...] Deveria também ser possível avaliar a quantidade do trabalho docente, mesmo em termos qualitativos, se existissem padrões de desempenho claros e se os gestores fossem capazes de aplicar esses padrões de modo consistente (2009, p. 201).

Existem diversas medidas de avaliação docente adotadas por diferentes países. No âmbito das escolas, a opção mais óbvia seria de perguntar aos alunos sobre o desempenho dos seus professores. Porém, este método envolve riscos como o de considerar bons aqueles professores que são mais benquistos pelos estudantes. Outro caminho de aferição mais utilizado, em âmbito sistêmico, é o uso de provas de conhecimento, já que pressupõe que o professor precisa ter domínio dos conteúdos para ensiná-los. Há também a metodologia denominada "método do valor agregado", na qual por complexos procedimentos estatísticos e acompanhando longitudinalmente o desenvolvimento dos alunos, os pesquisadores procuram separar, através deste método, o que os alunos sabem e aprenderiam mesmo sem a escola e aquilo que efetivamente assimilaram ao frequentar as aulas. Em teoria, assim seria possível discriminar com mais exatidão o quanto do avanço estudantil poderia ser creditado a bons professores.

Pode-se considerar, também, técnicas de avaliação com filmagens de aulas, análise de portfólios de professores e propostas de aula. Estas estratégias vêm sendo valorizadas por permitir um acompanhamento mais efetivo do que acontece em sala. Ao mesmo tempo, o registro permite um acompanhamento mais individualizado do docente. Na UNEB, nesta disciplina, o portfólio teve esse caráter de pesquisa da prática, através da escrita reflexiva.

Um dos métodos mais polêmicos de avaliação dos professores é por meio do resultado de seus alunos. No Brasil, isso vem sendo feito por estados como São Paulo e Rio Grande do Sul, como estratégias de identificar escolas (e não professores, individualmente) que registram avanços nos indicadores de rendimento nas provas oficiais. Nesses estados, o modelo de focar no desempenho dos alunos para instituir a medida da qualidade docente subsidiou as políticas de bonificação por desempenho. No entanto, o resultado dos alunos nas avaliações não revela as condições de trabalho do docente e os contextos sociais envolvidos. 
Outra forma que pode ser adotada pelas escolas é a autoavaliação, ou seja, quando os professores preenchem questionários sobre o próprio desempenho e estabelecem planos de aprimoramento ou de metas acordados com os colegas ou os diretores. A autoavaliação, embora vulnerável a distorções, é um recurso que vem sendo valorizado, pois é um complemento necessário ao olhar externo - permitindo contextualizar os resultados do avaliador que não vive o cotidiano da escola.

Um projeto realizado pela Fundação Bill \& Melinda Gates - Measures of Effective Teaching (MET, Medidas da Eficácia Docente, em tradução livre) - traz uma perspectiva complementar à autoavaliação: a possibilidade de que os docentes apontem, no questionário, suas condições de trabalho, características do ambiente da escola e o apoio que recebem para trabalhar.

A partir de todos os métodos de avaliação docente citados, alguns países adotam e consideram mais adequada o que se denomina "triangulação", ou seja, combinam diferentes perspectivas que garantam uma análise mais objetiva do trabalho docente.

Assim, refletir sobre a implementação e acompanhamento de padrões de qualidade na educação torna-se uma tarefa essencial para o estabelecimento de processos de avaliação que visem à melhora do desempenho (RODRIGUES, 2012). No Brasil, desde 2010, discute-se uma iniciativa do INEP/MEC de se estabelecer a Prova Nacional de Concurso para o Ingresso na Carreira Docente. Segundo o site do INEP/MEC (INEP, 2016), a Prova Nacional de Concurso tem o objetivo principal de subsidiar os Estados, o Distrito Federal e os Municípios na realização de concursos públicos para a contratação de docentes para a educação básica. As equipes técnicas do INEP/MEC consultaram os padrões estabelecidos para a profissão docente em sete países: na Austrália, no Canadá, em Cingapura, no Chile, em Cuba, nos Estados Unidos e na Inglaterra para levantar os fatores comuns ao perfil de um bom professor e que podem ser utilizados como critérios para avaliação da carreira docente. Como resultado, 20 fatores foram considerados recorrentes e serviram de base para a composição dos temas gerais que norteiam a elaboração da matriz de referência da Prova Nacional de Concurso para o Ingresso na Carreira Docente (Quadro 1).

Quadro 1. Fatores selecionados pelo INEP/MEC.

\begin{tabular}{|l|l|}
\hline 1 & $\begin{array}{l}\text { Domina os conteúdos curriculares das disciplinas que leciona, o que inclui a compreensão de seus } \\
\text { princípios e conceitos. }\end{array}$ \\
\hline 2 & $\begin{array}{l}\text { Conhece as características de desenvolvimento dos alunos, suas experiências e contexto em que } \\
\text { vivem, e como esses fatores afetam sua aprendizagem. }\end{array}$ \\
\hline 3 & Domina a didática das disciplinas que ensina, incluindo diversas estratégias e atividades de ensino. \\
\hline 4 & Domina o currículo ou as diretrizes curriculares das disciplinas que leciona. \\
\hline 5 & $\begin{array}{l}\text { Organiza os objetivos e conteúdos de maneira coerente com o currículo, os momentos de } \\
\text { desenvolvimento dos alunos e seu nível de aprendizagem. }\end{array}$ \\
\hline 6 & $\begin{array}{l}\text { Seleciona recursos de aprendizagem de acordo com os objetivos de aprendizagem e as } \\
\text { características de seus alunos. }\end{array}$ \\
\hline 7 & $\begin{array}{l}\text { Seleciona estratégias de avaliação coerentes com os objetivos de aprendizagem, a disciplina que } \\
\text { ensina e o currículo, permitindo que todos os alunos demonstrem o que aprenderam. }\end{array}$ \\
\hline 8 & $\begin{array}{l}\text { Estabelece um clima favorável para a aprendizagem, baseado em relações de respeito, equidade, } \\
\text { confiança, cooperação e entusiasmo. }\end{array}$ \\
\hline 9 & $\begin{array}{l}\text { Manifesta altas expectativas em relação às possibilidades de aprendizagem e desenvolvimento de } \\
\text { todos os seus alunos. }\end{array}$ \\
\hline 10 & $\begin{array}{l}\text { Estabelece e mantém normas de convivência em sala de aula, de modo que os alunos aprendam a } \\
\text { ter responsabilidade por sua aprendizagem e pela dos colegas. }\end{array}$ \\
\hline 11 & $\begin{array}{l}\text { Demonstra valores, atitudes e comportamentos positivos e promovem o desenvolvimento deles } \\
\text { pelos alunos. }\end{array}$ \\
\hline
\end{tabular}


Quadro 1. Continuação.

\begin{tabular}{|c|c|}
\hline 12 & $\begin{array}{l}\text { Comunica-se efetivamente com os pais de alunos, atualizando-os e buscando estimular o seu } \\
\text { comprometimento com o processo de ensino-aprendizagem dos alunos. }\end{array}$ \\
\hline 13 & $\begin{array}{l}\text { Aplica estratégias de ensino desafiantes e coerentes com os objetivos de aprendizagem e com os } \\
\text { diferentes níveis de aprendizado dos alunos. }\end{array}$ \\
\hline 14 & $\begin{array}{l}\text { Utiliza métodos e procedimentos que promovem o desenvolvimento do pensamento e da busca } \\
\text { independente do conhecimento. }\end{array}$ \\
\hline 15 & $\begin{array}{l}\text { Otimiza o tempo disponível para o ensino, garantindo o máximo de aprendizagem de cada aluno } \\
\text { durante toda a duração da aula. }\end{array}$ \\
\hline 16 & a educacional e as políticas vigentes. \\
\hline 17 & $\begin{array}{l}\text { Busca aprimorar seu trabalho constantemente a partir de diversas práticas, tais como: a reflexão } \\
\text { sistemática de sua atuação, a autoavaliação em relação ao progresso dos alunos, às descobertas de } \\
\text { pesquisas recentes sobre sua área de atuação, e às recomendações de supervisores, tutores e } \\
\text { colegas. }\end{array}$ \\
\hline 18 & $\begin{array}{l}\text { Trabalha em equipe com os demais profissionais para tomar decisões em relação à construção e/ou } \\
\text { à implementação do currículo e de outras políticas escolares. }\end{array}$ \\
\hline 19 & $\begin{array}{l}\text { Possui informação atualizada sobre as responsabilidades de sua profissão, incluindo aquelas } \\
\text { relativas à aprendizagem e ao bem-estar dos alunos. }\end{array}$ \\
\hline 20 & $\begin{array}{l}\text { Avalia e monitora o processo de compreensão e apropriação dos conteúdos por parte dos } \\
\text { estudantes. }\end{array}$ \\
\hline
\end{tabular}

Fonte: INEP (2016).

No que diz respeito à autoavaliação docente durante o estágio supervisionado, verificouse que dentre os fatores que possam ter influenciado o baixo desempenho da maioria dos alunos na avaliação da disciplina de Biologia, pode-se citar o período da última unidade do ano letivo, em que os alunos já estavam cientes do total de pontos que precisariam para ser aprovados na disciplina, e por isso não se empenharam em realizar todas as atividades de modo satisfatório. Pode estar relacionado também ao fato de que a IV unidade foi realizada em um curto período de tempo, porém com muitos conteúdos, que pode ter culminado na dificuldade dos alunos em assimilar a quantidade de conteúdos em pouco tempo, mas que, por outro lado, os alunos sairiam prejudicados caso o conteúdo programático do ano letivo não fosse trabalhado. A falta de aulas práticas em laboratório também pode ser citado, já que os conteúdos referentes à citologia exigem equipamentos para sua visualização (sendo o microscópio imprescindível), porém, uma vez que o laboratório da escola necessitava de reparos em seus equipamentos, as aulas práticas não puderam ser realizadas.

Embora possam ter ocorrido alguns fatores negativos para o processo ensinoaprendizagem, que podem ter gerado como conseqüência o baixo rendimento dos alunos na disciplina de Biologia, durante o estágio também foram aplicadas metodologias para mitigar as dificuldades encontradas, a exemplo de aplicação de jogo didático e demonstrações didáticas.

Tal estudo de caso, aqui descrito, possibilitou pesquisa da prática docente no exercício do processo de ensino-aprendizagem.

Dado o carácter contextualizado do conhecimento profissional do professor, o estudo de episódios de ensino, ou que impactam neste, na perspectiva de casos apresenta-se-nos como uma estratégia interessante na formação de professores, quer num ambiente de auto-formação quer em situações de formação colaborativa e supervisiva (INFANTE et al., 1996, p. 158). Grifo dos autores. 
Deste modo, a experiência do estágio de regência foi fundamental para formação do profissional docente, além de evidenciar a relevância da constante avaliação de suas práticas.

\section{CONCLUSÕES}

Os estágios supervisionados são de extrema importância para inserir os futuros professores biólogos no processo de reflexão da prática, em consonância com as teorias aprendidas, bem como para que se inicie a consciência da importância de se desenvolver profissionalmente. Discutir a avaliação docente é uma temática bastante ampla que não envolve somente as questões relativas ao desempenho docente, mas envolve analisar o processo de ensino-aprendizagem e as relações entre alunos, professores, escola, governo e sociedade. Faz necessário definir o que se entende por bom ensino e, a partir deste consenso, decidir o quê, para quê e como avaliar o desempenho docente na atualidade.

As avaliações docentes são de grande importância para fomentar o debate acerca da qualidade de ensino. Sendo assim, contribuem para a discussão e posterior delineamento de soluções que permitam enfrentar o desafio de superação do déficit de aprendizagem apresentado pelos alunos das redes públicas brasileiras de ensino.

\section{AGRADECIMENTOS}

À equipe escolar do Colégio Modelo Luis Eduardo Magalhães, em especial à professora Neide Sales, e à turma do primeiro ano do ensino médio por viabilizar a realização do estágio de regência. E sobretudo à professora Cláudia Regina Teixeira de Souza pela orientação e acompanhamento durante o estágio.

\section{REFERÊNCIAS}

ALARCÃO, I. Professores reflexivos em uma escola reflexiva. 8 ed. São Paulo: Cortez, 2011.

CARNOY, M. A vantagem acadêmica de Cuba: por que seus alunos vão melhor na escola. São Paulo: Ediouro, 2009.

FERNANDES, D. Avaliação do desempenho docente: desafios, problemas e oportunidades. Lisboa: Texto Editores, 2008.

FLORES, M. A.; VEIGA SIMÃO, A. M. (Orgs.). Aprendizagem e desenvolvimento profissional de professores: contextos e perspectivas. Mangualde: Edições Pedago, 2009. (Colecção Educação e Formação).

HANUSHEK, E.; WOESSMANN, L. Universal basic skills: what countries stand to gain. Paris: OECD Publishing, 2015. http://dx.doi.org/10.1787/9789264234833-en

INEP. Referenciais para o Exame Nacional de Ingresso na Carreira Docente. Disponível em:

$<$ http://consultaexamedocente.inep.gov.br/publico/download/Referenciais_para_o_Exame_Naci onal_de_Ingresso_na_Carreira_Docente.pdf> Acesso em: 29 de fevereiro de 2016.

INFANTE, M. J.; SILVA, M. S.; ALARCÃO, I. Descrição e análise interpretativa de episódios de ensino: os casos como estratégia de supervisão reflexiva. In: ALARCÃO, I. (Org.). Formação reflexiva de professores: estratégias de supervisão. Porto, Portugal: Porto Editora, 1996. (Coleção CIDINE 1). 
OCDE - Organização para a Cooperação e Desenvolvimento Econômico. Who are the lowperforming students? Paris: OECD Publishing, 2016. (PISA in Focus, No. 60). http://dx.doi.org/10.1787/5jm3xh670q7g-en

PIMENTA, S. G.; LIMA, M. S. L. Estágio e docência. São Paulo: Cortez, 2004.

RODRIGUES, S. S. Políticas de avaliação docente: tendências e estratégias. Ensaio: aval. pol. públ. Educ., v. 20, n. 77, p. 749-768, 2012. 